\title{
Trabalho em saúde e a implantação do acolhimento na atenção primária à saúde: afeto, empatia ou alteridade?
}

\author{
Alessandro da Silva Scholze ${ }^{1}$ \\ Carlos Francisco Duarte Junior ${ }^{2}$ \\ Yolanda Flores e Silva ${ }^{3}$
}

SCHOLZE, A.S.; DUARTE JUNIOR, C.F.; FLORES E SILVA, Y. Health work and the implementation of user embracement in primary healthcare: affection, empathy or alterity?. Interface - Comunic., Saude, Educ., v.13, n.31, p.303-14, out./dez. 2009.

We conducted a theoretical reflection on the work of primary healthcare professionals in the scope of user embracement, searching for possibilities to overcome alienation in their production process, based on experience reports regarding user embracement implementation in primary healthcare services. We identified the following theoretical perspectives which we consider useful in order to enhance humanization in the work in the health area and also to foster subjectivity in interpersonal relationships: affection, empathy and alterity. Although they are closely related to each other, we believe alterity is the theoretical perspective that is able to give the health worker conditions to develop user embracement while ensuring his/her own humanization. Alterity opens possibilities to cope with everyday situations in the healthcare services, providing health professionals with the conditions to work without restricting themselves to a biomedical point of view and, at the same time, preserving their own health.

Keywords: User embracement. Healthcare services. Primary healthcare.

Interdisciplinary research.
Desenvolvemos uma reflexão teórica sobre o trabalho na Atenção Primária à Saúde (APS) na diretriz do acolhimento, buscando possibilidades de superar a alienação em seu processo produtivo, a partir de relatos de experiência da implantação do acolhimento em serviços de APS. Identificamos as seguintes perspectivas teóricas nas relações interpessoais nos serviços, com indicadores de avanços na humanização do trabalho em saúde e de uma aproximação com a subjetividade: afeto, empatia e alteridade. Ainda que todas sejam adequadas e mesmo complementares entre si, fazemos nossa opção pela alteridade como perspectiva teórica capaz de instrumentalizar o trabalhador da saúde para desenvolver o acolhimento, sem deixar de garantir sua própria humanização. Esta abre possibilidades de enfrentamento das situações do cotidiano dos serviços de saúde, oferecendo aos profissionais condições de construírem seu trabalho sem limitá-lo à perspectiva biomédica e preservando sua própria saúde.

Palavras-chave: Acolhimento. Serviços de saúde. Atenção primária à saúde. Pesquisa interdisciplinar.
${ }^{1}$ Curso de Medicina, Universidade do Vale do Itajaí (UNIVALI). Rua 3050, 300, apto. 101, Centro. Balneário Camboriú, SC, Brasil. 88.330-308.

alessandroscholze@univali.br ${ }^{2}$ Curso de Medicina, UNIVALI.

${ }^{3}$ Mestrado Profissional em Saúde da Família e Gestão do Trabalho, UNIVALI. 


\section{Introdução}

A Política Nacional de Humanização (PNH) da Atenção e Gestão no Sistema Único de Saúde, chamada Humaniza SUS, foi desenvolvida de modo a qualificar o SUS e estabelecer, na prática, suas diretrizes. Essa política foi uma resposta às evidências do despreparo dos profissionais da saúde para lidar com a dimensão subjetiva do cuidado, juntamente com a persistência de modelos de gestão centralizados e verticais, que desapropriam o trabalhador de seu processo de trabalho (Brasil, 2006a).

A PNH definiu como humanização "a valorização dos diferentes sujeitos implicados no processo de produção de saúde: usuários, trabalhadores e gestores" (Brasil, 2006a, p.10). Esta deve ser implementada com base nos seguintes princípios: transversalidade, qualificando a comunicação no sistema; indissociabilidade entre atenção e gestão, garantindo a integralidade do cuidado ao identificá-lo com os processos de trabalho e produção de saúde; protagonismo, corresponsabilidade e autonomia dos sujeitos e coletivos. Este último relaciona-se diretamente com o entendimento do trabalho como forma de produção de sujeitos, assumindo que a autonomia destes nos processos de gestão e cuidado garante maior efetividade nas mudanças do sistema de saúde.

$\mathrm{O}$ acolhimento é uma das diretrizes da PNH e tem se tornado sua face mais visível, especialmente na Atenção Primária à Saúde (APS), pelas consequências diretas que pode determinar no acesso dos usuários como uma mudança no processo de trabalho, a fim de atender todos aqueles que buscarem o serviço de saúde. Desse modo, o princípio da universalidade é estabelecido de forma qualitativa, não apenas pelo aumento no número de unidades ou profissionais na rede de saúde, mas pela inclusão de toda a equipe de saúde no processo de atenção, aproveitando a capacidade clínica de profissionais que apenas serviam de intermediários para a consulta médica. Esses profissionais devem criar espaços no serviço de saúde que permitam uma escuta qualificada, conduzindo à responsabilização pelo problema do usuário e dando-lhe uma resposta adequada (Brasil, 2006a; Silveira, 2004; Malta et al., 1998).

A PNH propõe o acolhimento como processo constitutivo das práticas de produção e promoção da saúde, preocupando-se em incluir a saúde do trabalhador em saúde como parte das metas do SUS e de seus parâmetros de avaliação. Porém, as propostas da PNH conduzem tanto a possibilidades de humanização do trabalho no SUS como a novas exigências, capazes de sobrecarregar ainda mais os profissionais de saúde, caso estes não estejam instrumentalizados para lidar com o aumento de demanda gerado na ampliação qualitativa da universalidade e pela qual devem se responsabilizar.

Nesse caso, ainda que bem intencionada, a proposta da humanização com base no acolhimento gera condições adicionais para o surgimento da Síndrome de burnout do trabalhador em saúde. Reconhecida como uma das principais doenças nos Estados Unidos e na Europa, o burnout é um risco ocupacional para pessoas envolvidas nos cuidados em saúde, iniciado com excessivos e prolongados estados de tensão no trabalho, atingindo mais intensamente os não especialistas, como as auxiliares de enfermagem. Suas manifestações incluem: exaustão emocional, perda de interesse em práticas profissionais inovadoras e sintomas físicos diversos, com consequente perda de qualidade no trabalho e distanciamento nas relações pessoais (Trigo; Teng, Hallak, 2007).

O sofrimento no trabalho pode ainda ser mantido pelo desenvolvimento de estratégias defensivas que garantem a normalidade aparente e insensibilizam contra o que faz sofrer, como as demandas lançadas ao trabalhador em saúde para construir um ambiente de humanização e acolhimento dentro de um sistema que nega a subjetividade do trabalhador e do usuário. Esse trabalhador protege sua saúde mental, de modo a tornar tolerável o sofrimento ético que experimenta ao infligir um sofrimento indevido ao outro, objetificando-o e a si mesmo num processo de produção de procedimentos, e não de saúde (Dejours, 1999).

Diante disso, construímos este artigo a partir de uma pesquisa de natureza bibliográfica/teórica sobre o trabalho dos profissionais de saúde na perspectiva do acolhimento na APS no Brasil, com base nas categorias afeto, empatia e alteridade, apontadas como possibilidades teóricas para superar a alienação em seu processo produtivo (Mayema, 2007; Brasil, 2006a, 2006b; Teixeira, 2005, 2004). Inspirando-nos em Minayo (2007), relacionamos tais possibilidades bibliográficas/teóricas com relatos de situações práticas de implantação do acolhimento na APS, coletados em artigos científicos identificados nas bases de dados da Bireme com a temática "acolhimento", especificando-se "serviços de saúde", de 1998 a 
2008, e considerando a descrição das primeiras experiências até as mais atuais. O resultado dessa busca indicou 13 textos, dos quais apenas três descreviam experiências. Considerando o número de textos disponíveis para análise, escolhemos "acolhimento" e "APS" como nossos novos descritores de busca e selecionamos outros nove trabalhos. A análise e a interpretação do material disponível resultaram da leitura compreensiva dos textos selecionados, problematização das ideias aí contidas sobre implantação do acolhimento e humanização do trabalho, conduzindo-se um diálogo com as categorias previamente identificadas para elaborarmos uma síntese interpretativa.

\section{Trabalho e cuidado na saúde}

Segundo Zarifian (2002, p.10), "todo trabalho caracterizado profissionalmente pode ser definido nos seguintes termos: conduzir um devir, mobilizando a experiência passada e antecipando o porvir". A hegemonia do capitalismo industrial tornou-se viável pela instituição da autodisciplina na organização do tempo que passou a permear toda a atividade social, organizada e reforçada pela disciplina industrial. A existência de um tempo homogêneo, caracterizando o tempo do porvir, permitiu comparar e controlar trabalhos heterogêneos, relacionando-os com um padrão comum, ou seja, o tempo necessário para produzir uma unidade de mercadoria. E, num aspecto mais amplo, possibilitou organizar os acontecimentos, relações sociais e fazer previsões nesse tempo espacializado em torno de um referencial comum, rigorosamente homogêneo, que contabiliza a passagem de minutos, dias ou anos.

Dotado de tanta utilidade social, o tempo espacializado não tem sentido próprio nem valor ético, mas foi incorporado na organização taylorista do trabalho, definindo cada gesto e movimento do trabalhador, sempre repetidos da mesma forma no presente. Já, quando atualmente aplicada aos prazos para realização de certa tarefa, a pressão do tempo pode ser simplesmente transferida do gesto do trabalhador para a impaciência do cliente ou, alternativamente, ser negociada numa interação entre trabalhadores e clientes, determinada pela qualidade concreta do serviço, e não pela ditadura abstrata do tempo homogêneo. Assim, o trabalho volta-se para o tempo do devir, simultaneamente objetivo e subjetivo, integrando as memórias e as experiências do passado em um presente que apenas serve ao fluxo das transformações que conduzem às diferentes possibilidades do futuro (Zarifian, 2002).

Também na saúde, o trabalho coletivo costuma ser organizado de forma taylorista, fragmentando-se a atividade produtiva em diferentes parcelas executadas por trabalhadores especializados em cada uma das ações necessárias ao cumprimento da tarefa. Tal divisão técnica do trabalho em saúde é característica do sistema de produção capitalista, determinando a padronização das tarefas de forma hierarquizada e afastando o profissional da saúde do controle do processo de cuidado, com isso há perda da autonomia e alienação desse profissional. O foco do trabalho passa a ser a execução de procedimentos repetitivos, em um tempo espacializado que exclui o trabalhador do processo criativo e das decisões sobre o cuidar (Pires, 2006a, 2006b; Campos, 1998).

Essa característica excludente foi definida por Boff (1999) como um dos modos de ser-no-mundo: o trabalho, em oposição ao modo-de-ser cuidado. A partir desses modos possíveis, o ser humano desenvolve seus processos de construção da realidade. $O$ trabalho surgiu como interação do homem com a natureza, evoluindo para uma relação progressivamente mais intervencionista em seu meio, formando culturas que modelaram a natureza e os próprios humanos. Isso foi possível somente adotando certo distanciamento da natureza, a fim de analisá-la e dominar seus processos. Assim, a lógica do ser-no-mundo trabalho é antropocêntrica, negando as conexões do humano com a natureza. Por extensão, essa lógica do trabalho aplicada na própria sociedade humana pode acabar por objetificar e subjugar também as pessoas, como fins para atingir objetivos de produção e consumo.

Já o modo-de-ser cuidado seria a essência do ser humano, que não se opõe necessariamente ao modo-de-ser trabalho, mas dele diferencia-se por manter uma relação de convivência sujeito-sujeito com a natureza e entre os seres humanos. Desse modo, a intervenção sobre um objeto é substituída pelo acolhimento e pelo respeito, com os quais o humano dirige-se aos elementos da natureza e da sociedade por seu valor intrínseco e não utilitário. O cuidado, na visão de Boff (1999), é sistêmico, existe na relação entre os elementos do mundo, bem como na relação entre os elementos do próprio ser humano. Exige-se, então, uma integralidade no cuidado com o humano que passa pelo ambiente no 
qual vive, a sociedade na qual convive com outros seres humanos, até suas próprias individualidades físicas, espirituais e mentais.

Por sua vez, Maturana (1997) definiu o humano a partir da linguagem que surgiu da intimidade na vida dos antepassados do homem que coordenavam suas ações ao compartilharem alimentos, participarem da criação dos filhos, exercerem sua sensualidade na vida cotidiana. Essas condutas consensuais coordenadas nos pequenos grupos eram, por sua vez, coordenadas pela linguagem, a qual tem uma base emocional; sem esta, a convivência não seria possível. O linguajar e a capacidade de se emocionar reúnem-se para constituir uma forma específica de diálogo ou conversação, definindo o modo de viver do grupo humano considerado.

A convivência nos grupos humanos se dá por interações recorrentes. Quando essas interações "recorrem" de forma espontânea, levando à coexistência dos elementos do grupo em aceitação mútua, identifica-se o amor como fenômeno biológico. O amor expressa uma congruência estrutural entre sistemas vivos que, no caso humano, pode acontecer nas diferentes formas possíveis de viver juntos, mais próximas ou mais casuais, desde que baseadas na aceitação mútua. A emoção do amor origina o fenômeno social. Assim, um sistema social humano existe quando seres humanos coordenam suas ações no viver em aceitação mútua, sem a qual o sistema não se define como social. Por outro lado, não são sistemas sociais os sistemas de trabalho, voltados para a realização de uma tarefa, o que exige o compromisso com a emoção que constitui esse espaço de relações. Da mesma forma, os sistemas hierárquicos, "que são [...] constituídos sob a emoção que configura as ações de autonegação e negação do outro na aceitação da submissão própria ou da do outro [...] não são sistemas sociais" (Maturana, 1997, p.177).

Nesse sentido, os serviços de saúde aproximam-se mais da definição de aparelhos do que daquela de redes, entendendo-se aparelhos como organizações de agentes sociais caracterizados por dirigirem suas ações a um público, ou seja, o conjunto de indivíduos com o qual mantém uma relação de exterioridade, destinando a ele sua produção, enquanto estabelece internamente sua estrutura e processos de regulação. Já as redes definem-se por não terem um público e, independentemente de quais formas assumam, todas estabelecem estruturas fracamente hierarquizadas e muito mais flexíveis em relação aos aparelhos, sendo constituídas por entidades relativamente autônomas, a partir de um princípio dinâmico de autorregulação. Os aparelhos na sociedade moderna frequentemente agem de forma a excluir o interesse dos usuários, assumindo um paradigma produtivista centrado não nas relações produtor-usuário, mas no produto, ou procedimento, em si mesmo (Godbout, 2004).

Assim, alguns recursos utilizados pelas pessoas doentes, nos seus itinerários em busca de cura e cuidado, encontram-se imersos em sistemas sociais como a família; enquanto outros, incluídos no sistema de saúde formal ou profissional, mobilizam sistemas de trabalho. No primeiro caso, partimos do pressuposto de que neste sistema existe aceitação mútua e, consequentemente, a responsabilização e o desvelo necessários ao cuidado devem estar presentes. Os sistemas de trabalho, entretanto, prescindem da aceitação mútua, expondo os doentes à possibilidade de serem subjugados pelo modo-de-ser trabalho, como meros objetos de procedimentos ou consumidores de health commodities (Scholze, Silva, 2005; Helman, 2003).

Diante desses intercâmbios possíveis, nas redes do indivíduo ao longo de seus itinerários de cura e cuidado, e da expectativa que os serviços de saúde contribuam para a cura e o cuidado, cabe o questionamento: de que forma os serviços de saúde, estabelecidos como sistemas de trabalho, podem estar aptos a produzirem cuidado de forma integral? Também cabe a nós perguntarmos o que é este 'cuidado integral', para não chegarmos a um conceito semelhante ao de 'saúde', vinculado pela Organização Mundial da Saúde (OMS) nas décadas de 1970 e 1980, que sofreu tantas críticas entre profissionais da área. Neste momento, considerando a alteridade dos seres humanos, podemos inferir que um 'cuidado integral' é tão amplo e tão distinto quanto as culturas humanas existentes, e que para cada ser humano existe um cuidado necessário segundo seus problemas de saúde, aceitação do cuidado e o 'olhar' cultural que esta pessoa lançará sobre o 'cuidador' e sobre as terapêuticas (ou 'atos em Saúde') que este indicará em seu itinerário de cura e cuidado.

Mehry (1998) considerou que o trabalho em saúde tem como produto os "atos em Saúde", cuja finalidade seria intervir nos problemas de saúde, pressupondo um impacto positivo sobre as 
necessidades em saúde dos usuários dos serviços. Porém, o foco de seu trabalho pode ser esse usuário ou a produção de procedimentos, sendo que, neste último caso, a produção de atos em Saúde esgotase na produção do procedimento, independentemente de seu impacto sobre a saúde de uma pessoa ou população. O autor entendeu que os usuários se voltam para os serviços de saúde menos em busca de procedimentos do que esperando encontrar espaços que disponibilizem acolhimento, responsabilização e vínculo. Porém isso não limita o foco do trabalho em saúde apenas na produção dessas relações, sendo necessária também a competência para responder aos problemas de saúde, sejam ou não disfunções biológicas.

O autor reconheceu, ainda, uma dimensão cuidadora, envolvendo os núcleos de saber característicos de cada profissão da saúde, a ser explorada juntamente com os conhecimentos técnico-científicos para desenvolver o acolhimento e a responsabilização, buscando aumentar a resolutividade da atenção em saúde e autonomizar o usuário. Concomitantemente, a interpretação exclusivamente biomédica das doenças deveria ser ampliada para incluir as diferentes práticas de cura existentes na sociedade e as experiências dos pacientes que não se enquadram nos diagnósticos preestabelecidos do instrumental teórico biomédico vigente. A partir dessas mudanças no modelo de atenção à saúde, é possível vislumbrar uma assistência que se destine ao cuidado integral à saúde, de forma que o modo-de-ser trabalho esteja subordinado ao modo-de-ser cuidado (Tesser, Luz, 2002; Merhy, 1998). Para que seja possível ampliar o instrumental de ação dos profissionais da Saúde, as mudanças nos serviços deveriam incluir a discussão sistemática do modo-de-ser de trabalho versus modo-de-ser do cuidado, em diversas perspectivas, incluindo-se aí a inserção de estudos antropológicos, sociológicos, geográficos, históricos, éticos e de relações humanas, entre outras possibilidades. Importante enfatizar que estes conhecimentos são oferecidos em muitos cursos de graduação e pós-graduação, contudo a superficialidade dos mesmos, a entrega destes conteúdos a pessoas sem experiência na saúde e a ideia de que estas disciplinas apenas servem para confirmar as horas obrigatórias do Ministério da Educação comprometem em muito o interesse dos profissionais pelos conteúdos ministrados.

\section{Experiências no acolhimento}

Nesse contexto teórico, o acolhimento constitui-se em um elemento da mudança no processo de trabalho em saúde, com potencial de ampliar as práticas de cuidado envolvidas nas ações dos profissionais de saúde, porém esse potencial pode ser restringido pelo contexto prático no qual o acolhimento será estabelecido. O contexto do trabalho em saúde hegemônico na atualidade é aquele do modo-de-ser trabalho, voltado para a produção de procedimentos e muito bem adaptado à estrutura dos serviços de saúde organizados como aparelhos.

As diferentes experiências na implantação do acolhimento já desenvolvidas estiveram voltadas para implementar uma escuta ampliada, capaz de identificar os motivos que levaram o usuário a buscar o serviço, identificando suas necessidades e dando encaminhamento para a solução de seus problemas. Em algumas propostas foram criadas equipes de acolhimento, compostas por diferentes profissionais, enquanto outras se centraram especialmente nos auxiliares de enfermagem, os quais recorreriam a outros membros da equipe de saúde quando necessário. Porém, eventualmente, estes auxiliares encontravam-se em unidades sem locais adequados para a escuta do paciente e sem o envolvimento do restante da equipe, não sendo eles mesmos acolhidos (Mayema, 2007; Campos, Carpintero, Bueno, 2001; Costeira, s/d).

As dificuldades iniciais na experiência com acolhimento costumavam envolver o temor diante das novas iniciativas, exacerbadas pela ênfase que o acolhimento dava a problemas já existentes, mas não percebidos, criando uma falsa noção da Unidade Básica de Saúde (UBS) como pronto-atendimento (Franco, Bueno, Merhy, 1999). Essa percepção foi corroborada quando os usuários relacionavam o acolhimento diretamente com a pontualidade dos médicos e a rapidez no atendimento da recepção, em unidades que preservavam um trabalho na forma médico-centrada, a partir da distribuição de fichas (Ramos, Lima, 2003). Esta mesma óptica foi mantida pelos próprios membros da ESF, que relacionavam a organização do processo de trabalho da equipe com a falta de acesso ao atendimento clínico, e percebiam a Estratégia Saúde da Família como dirigida aos excluídos. Considerando esta premissa, não 
viam necessidades de maiores investimentos, mas viam como correta (e, muitas vezes, como a assistência mais adequada) a atuação de auxiliares de enfermagem na recepção, ainda que orientada por opções limitadas de encaminhamento, utilizando a referência ao pronto-atendimento de acordo com a organização do trabalho, em lugar da necessidade do usuário. Com isto, o que verificamos foi a ampliação de um sistema de distribuição de senhas e preservação do não acesso à disputada agenda médica (Schimith, Lima, 2004).

Equipes com atividade docente-assistencial vivenciaram essa situação diante de populações diversas daquelas originalmente abrangidas, ao receberem moradores de rua, moradores de favela e profissionais do sexo, entre outros, para os quais as rotinas programáticas não se mostravam adequadas. Desse modo, estabeleceu-se um acolhimento não apenas de caráter pontual, mas, a partir da identificação de situações de vulnerabilidade, no qual a organização do processo de trabalho foi modificada para resgatar a cidadania dos usuários, na perspectiva da equidade e de uma discriminação positiva (Romano, 2008; Carneiro, Silveira, 2003).

Diferentes formas de organização do acolhimento em diferentes centros de saúde foram relatadas por Takemoto e Silva (2007), sendo que, em três das unidades estudadas, o auxiliar de enfermagem conduzia uma triagem qualificada, que levava a uma primeira consulta com o médico, favorecendo somente $o$ atendimento a queixas agudas numa modalidade de pronto-atendimento. Assim, não houve ampliação da resolutividade dos outros profissionais, ao contrário de outra unidade pesquisada, em que o acolhimento foi entendido como postura, buscando dar resposta às necessidades do usuário, ainda que não fossem clínicas. Esse tipo de vínculo é capaz de gerar satisfação e segurança, sendo fruto de um atendimento baseado na escuta e no bom desempenho dos profissionais, influenciando inclusive o acesso geográfico, pois o atendimento com resolutividade promove a procura por determinadas unidades, mesmo implicando maior deslocamento do usuário (Tresse, 2008; Lima et al., 2007).

Porém, mesmo que a implantação do acolhimento conduza os profissionais à prática dessa diretriz operacional, o deslocamento de algumas decisões - antes centradas no médico, para outros profissionais, como técnicos e auxiliares de enfermagem - pode não ser bem compreendido pelos usuários. Os possíveis conflitos entre as propostas de descentrar o trabalho da figura do médico e a concepção de atendimento em saúde trazida pelos usuários podem dificultar os esforços de comunicação, especialmente pela desvalorização dos profissionais que conduzem o acolhimento, gerando sobrecarga nas equipes de saúde, caso estas não sejam também acolhidas (Oliveira, Tunin, Silva, 2008; Pinafo, Lima, Baduy, 2008; Souza et al., 2008).

Uma forma de responder às possíveis resistências à implantação do acolhimento ou a sua implantação em formatos que têm pouco impacto no processo de trabalho é entendê-lo concomitantemente como postura dos profissionais e como técnica, objetivando a ampliação e a qualificação do acesso dos usuários. Para isso, contribui também uma implantação participativa do processo, com colegiados locais e o apoio de representantes do nível central. Assim, possibilita-se um aumento quantitativo do rendimento dos profissionais envolvidos e faz-se com que estes percebam uma maior qualificação no seu trabalho e na produção do cuidado, qualificando o vínculo com a comunidade e fortalecendo as equipes por meio da educação permanente (Alves et al., 2008; Oliveira et al., 2008; Solla, 2005; Panizzi, Franco, 2004).

\section{Possibilidades teóricas da humanização do trabalho no acolhimento}

Verificamos que a maior potencialidade das experiências do Acolhimento na APS tem sido a redução da demanda reprimida na rede básica, geralmente estabelecendo equipes de acolhimento centradas nos auxiliares de enfermagem. Porém, o acolhimento também pode ser explorado pelo enfoque de uma tecnologia do encontro trabalhador/usuário que, se adequada, permite desencadear um processo de mudança nas práticas de saúde, direcionando-as a partir das tecnologias leves (Carvalho; Cunha, 2006; Teixeira, 2004; Mehry, 1998).

Nesse sentido, os estudos consultados utilizaram diferentes termos para abordar os aspectos subjetivos das relações profissional-usuário, sendo identificáveis alguns marcos teóricos a partir dos quais os profissionais poderiam desenvolver suas práticas de saúde, de modo a qualificar sua interação com os 
sujeitos e coletivos, considerando-os em suas singularidades. Assim, buscaremos definir três desses possíveis marcos teóricos - afeto, empatia e alteridade - e analisar suas relações com o processo de trabalho em saúde como "maneiras adequadas de receber os distintos modos como a população busca ajuda nos serviços de saúde, respeitando o momento existencial de cada um sem abrir mão de pôr limites necessários" (Andrade, Barreto, Bezerra, 2008, p.821).

O termo afeto deriva originalmente da literatura psicanalítica, na qual se tentava descrever o tipo de sentimento que acompanhava ideias ou representações mentais de objetos externos, enquanto o humor seria a soma dos afetos. Manley (1999) sugeriu que se abandonasse a distinção de humor como um estado emocional prevalente em longo prazo, enquanto o afeto seria mais flutuante, buscando-se descrever os componentes objetivo e subjetivo da expressão emocional separadamente, podendo estes inclusive serem discordantes. Normalmente, verificadas nas variações da expressão facial, tom de voz e gestos, as manifestações externamente direcionadas do afeto podem permitir classificá-lo como: alegre, triste, embotado, expansivo, lábil, inapropriado, variando também na intensidade com que a emoção é expressa (Cordioli, Zimmermann, Keller, 2004; Sadock, 1999).

Teixeira (2004) utilizou o termo afeto ao definir o acolhimento dialogado como uma técnica de conversa, conduzida por determinadas emoções e afetos, de modo que as redes de trabalho em saúde formam extensas redes de conversações que podem ser pensadas como redes de trabalho afetivo, dedicadas a criar e a manipular afetos. Esse afeto estaria limitado, porém, à situação apriorística de aceitação do outro como um legítimo outro, no mesmo sentido que Maturana (1997) utilizou o termo "amor", sendo que aquele autor identificou esse afeto como acolhimento.

A capacidade de identificar os afetos no outro, por meio de sutis pistas sociais, é denominada empatia, uma habilidade baseada na autoconsciência emocional, fundamental para a efetividade interpessoal e citada como parte do processo de acolhimento (Demeneck, 2008). É uma das cinco áreas básicas que relacionam as habilidades definidoras da Inteligência Emocional, permitindo manifestar reações emocionais apropriadas a partir da autoconsciência. A raiz da palavra latina emoção é motere: "mover", implicando, com o prefixo "e", a conotação de mover para longe, ou seja, uma tendência de ação está implícita em cada emoção (Goleman, 1999).

Emoção se refere a um sentimento e aos pensamentos, estados psicológicos e fisiológicos, e toda a gama de impulsos para agir ligados a esse sentimento. Algumas são consideradas universais: raiva, tristeza, medo, alegria, amor, surpresa, desgosto, vergonha (Goleman, 1999). Também a palavra empatia denomina um sentimento que nos permite considerar uma perspectiva diferente da nossa própria, fazendo com que olhemos o sofrimento alheio com o olhar de quem sofre, apreciando a situação como se estivéssemos no lugar da pessoa que a experimenta. Na sua ausência, existe desconsideração pela pessoa do outro, seus valores, crenças e desejos (Goldim, 2006). Isso nos remete à definição de Boff (1999) do modo-de-ser cuidado, inviável sem o sentimento de empatia, que também é um dos atributos essenciais na relação médico-paciente e qualquer outra relação profissional na saúde em que se pense o cuidado como uma responsabilidade ética e moral do outro em um momento de fragilidade emocional e física (Morinaga et al., 2002).

Por sua vez, alteridade é um conceito central da Antropologia, ciência que nasceu do estudo das populações distantes, demandando o desenvolvimento de ferramentas, como a observação participante, para conduzir suas investigações. Ao longo de suas diferentes vertentes, a Antropologia preservou suas noções de distanciamento, seja no sentido de aproximar o que é longínquo, seja no de assumir um distanciamento da realidade próxima que permita um "estranhamento" desta, de modo a ver, como culturais, elementos de nossa própria sociedade que, por sua presença cotidiana, parecem-nos naturais. O olhar antropológico é voltado para o outro, para a alteridade. Essa alteridade incorpora a noção de humanidade plural, negando a existência de um centro do mundo ou de um centro do saber, e aceitando a diversidade de culturas que carregam suas próprias complexidades e maturidade (Laplantine, 2000). A ideia é não apenas a observação de diferentes realidades culturais, mas também adotar o ponto de vista do outro, buscando experimentar a realidade cultural alheia, a partir da própria alteridade (Helman, 1996). Dessa forma, reconhecemos o outro não apenas como objeto, mas também como um sujeito relacional em sua singularidade (Brasil, 2006a).

O nível de incorporação da alteridade no trabalho em saúde, ou competência cultural do profissional, pode variar da aceitação incondicional ao puro escárnio, considerando-se que, se não 
exploradas e comunicadas, as diferenças culturais no encontro entre profissional e usuário podem inviabilizar o cuidado (Betancourt, 2004). Ainda que não seja uma panaceia, a competência cultural desenvolvida a partir de uma postura de alteridade é necessária para garantir a qualidade das práticas de saúde, evitando assumir o usuário como passivo e ignorante diante dos profissionais de saúde, que seriam responsáveis absolutos pelo cuidado, quando, na verdade, é o primeiro que detém o poder de escolha quanto a que orientações seguir ou não (Oliveira, 2002).

O acolhimento, portanto, não se limita a um espaço físico disponível ou a uma postura dos profissionais em seu trabalho na saúde, mas depende de uma organização multidisciplinar no serviço de saúde que exige pessoal disposto para ir além da reflexão e problematização dos processos de trabalho, com garantia de tempo disponível e boa remuneração, além de uma infraestrutura que permita a eficácia do atendimento clínico. Tais condições são possíveis em uma cultura institucional aberta e flexível, na qual o poder seja intensamente delegado a gestores e a equipes técnicas qualificadas (Serrano, Benito, Giordani-Serrano, 2007).

Neste momento, percebemos que o sistema oficial de saúde, representado pelo Ministério da Saúde, ao tratar da saúde do 'outro' usuário, esquece-se do 'outro' funcionário deste sistema. Demonstra, desta forma, que a sua 'vontade' de humanizar os serviços baseia-se em ações para se 'ver' em estatísticas de assistência e muito pouco para realmente atuar numa perspectiva humanizadora que inclui o cuidado a todos: usuários diretos do sistema e trabalhadores deste mesmo sistema. Nesse sentido, nos últimos anos, a Antropologia vem se deparando com um dilema em suas ações: a necessidade de intervenção do antropólogo, e não apenas a observação, descrição e interpretação do que descobre em suas pesquisas, sobretudo na área da saúde. O dilema maior está em como oferecer as ferramentas de ação para outras áreas do conhecimento agirem, sem que estas, ao utilizarem as mesmas, não produzam os problemas descritos anteriormente. Do que falamos exatamente? Quando fornecemos aos dirigentes dos serviços de saúde respostas a suas indagações sobre como assistir melhor ao usuário considerando sua cultura e alteridade, proporcionamos meios que incluem ações diferenciadas que exigem dos trabalhadores da saúde maior disponibilidade de tempo, maior envolvimento emocional, físico e espiritual com o usuário, sem que este receba em igual volume condições para atuar nessa perspectiva. Olhando desta forma, o que temos são serviços superficiais que continuarão a ignorar o ser humano, visto que ignorar o trabalhador que atua na rede de saúde é tão grave quanto ignorar o usuário.

\section{Considerações finais}

No curso de sua breve história, o SUS promoveu claros avanços, ainda que, em geral, estes avanços não tenham revertido em amplo reconhecimento e apoio para sua efetivação, dada sua condição de movimento contra-hegemônico. Em vez disso, encontramos, de forma recorrente, tentativas de se construírem pontos de apoio para novos avanços, alguns sólidos e bem-sucedidos, outros de aspecto artificial e ignorando a existência de conhecimentos prévios ricos em potencialidades, em prol de novas nomenclaturas que correm o risco de se tornarem apenas novas vestes para antigas práticas.

$\mathrm{O}$ acolhimento pode se tornar apenas outra denominação de pronto-atendimento, caso o trabalhador da saúde não seja também acolhido. Os profissionais envolvidos nessa empreitada precisam desenvolver conceitos claros em relação a seu trabalho, evitando a sobrecarga, assumindo a participação nas decisões organizacionais e definindo claramente seus papéis como cuidadores, com comunicação clara e sem superenvolvimento que ameace sua integridade pessoal.

Assim, esta reflexão foge às pretensões de firmar respostas, limitando-se a construir algumas possibilidades teóricas em torno da humanização e do acolhimento, nas quais obtivemos mais claramente alguns pontos de partida para novos questionamentos do que fórmulas exatas para sua implantação. No entanto, isso é coerente com a perspectiva de redes de conversação fluidas, constantemente co-construindo as práticas nas interações entre os sujeitos que buscam ou oferecem apoio em meio ao processo saúde-doença.

Identificamos os marcos teóricos: afeto, empatia e alteridade como maneiras adequadas de atuar no acolhimento na APS, facultando também, aos profissionais de saúde, seus próprios avanços na 
humanização do seu trabalho. Esses marcos teóricos abrem possibilidades de releitura dessas relações, permitindo abordar as práticas em saúde na óptica do modo-de-ser cuidado, e mesmo relativizar a estrutura de aparelhos dos serviços de saúde, entendendo sua emoção fundamental não como a aceitação mútua incondicional do amor, mas que a emoção do compromisso fundamenta esse sistema de trabalho, voltando-se para a produção de saúde, não para o consumo de serviços ou produtos do complexo médico-industrial.

Mas, ainda que adequados e mesmo complementares entre si, fazemos nossa opção pela alteridade, como marco teórico capaz de instrumentalizar o trabalhador da saúde para desenvolver o acolhimento, sem deixar de garantir sua própria humanização. Essa opção se deve à caracterização do afeto não como apenas positivo nas relações humanas, mas trazendo em seu bojo todas as possibilidades emocionais, desde a alegria até a tristeza, devendo sempre ser compreendido, não apenas expressado, mesmo porque as responsabilidades éticas do profissional da saúde impedem-no de se guiar apenas emocionalmente, tanto quanto de ignorar as emoções do outro e suas próprias nos encontros desenvolvidos nas práticas em saúde. A compreensão dos afetos alheios deve-se, então, à empatia do profissional, cujo desenvolvimento demanda autoconhecimento e a capacidade de identificar as manifestações verbais ou não verbais, explícitas ou contraditórias, do sofrimento de outrem. Ainda assim, essas manifestações de afeto não seriam inconfundíveis ou exclusivas, pois sempre acabam por serem moduladas culturalmente.

A alteridade abre, então, possibilidades de enfrentamento das situações do cotidiano dos serviços de saúde, acolhendo o outro como sujeito em seu sofrimento, em lugar de constituir-se em torno da doença como objeto. Ao mesmo tempo, o profissional tem condições de construir seu trabalho a partir da alteridade, evitando ser etnocêntrico na perspectiva biomédica e preservando sua saúde mental, de modo a responsabilizar-se por seus esforços em conjunto com o outro, sem sofrer por inevitáveis insucessos decorrentes daquilo que não domina, os quais podem sempre ser encarados como oportunidades de aprendizagem. Tais oportunidades são enriquecidas quando se assume o distanciamento proposto pela alteridade em relação à realidade dos serviços de saúde, estranhando-a de modo a produzir mudanças, e superando a naturalização das situações que promovem o sofrimento do trabalhador e sua alienação.

\section{Colaboradores}

Os autores Alessandro da Silva Scholze e Carlos Francisco Duarte Junior participaram da elaboração do projeto, revisão da literatura, redação e revisão do texto. A autora Yolanda Flores e Silva participou da redação e revisão do manuscrito.

\section{Referências}

ALVES, C.R.L. et al. Análise do acolhimento de crianças e adolescentes para o planejamento das ações do PSF. Rev. Bras. Med. Fam. Com., v.3, n.12, p.247-56, 2008.

ANDRADE, L.O.M.; BARRETO, I.C.H.C.; BEZERRA, R.C. Atenção primária à saúde e estratégia saúde da família. In: CAMPOS, G.W.S. et al. (Orgs.). Tratado de Saúde Coletiva. 2.ed. São Paulo: Hucitec, 2006. p.783-36.

BETANCOURT, J.R. Cultural competence - marginal or mainstream movement? N. Engl. J. Med., v.351, n.10, p.953-5, 2004.

BOFF, L. Saber cuidar: ética do humano - compaixão pela terra. Petrópolis: Vozes, 1999.

BRASIL. Ministério da Saúde. Secretaria de Atenção à Saúde. Núcleo Técnico da Política Nacional de Humanização. HumanizaSUS: documento base para gestores e trabalhadores do SUS. Brasília: Ministério da Saúde, 2006a. Disponível em: <http://bvsms.saude.gov.br/ bvs/publicacoes/humanizaSus_doc_base.pdf>. Acesso em: 19 maio 2008. 
BRASIL. Ministério da Saúde. Secretaria de Atenção à Saúde. Núcleo Técnico da Política Nacional de Humanização. Acolhimento nas práticas de produção de saúde. 2.ed. Brasília: Ministério da Saúde, 2006b. Disponível em: <http://www.saude.rr.gov.br/humanizasus/ acolhimento_nas_praticas.pdf>. Acesso em: 19 maio 2008.

CAMPOS, G.W.S. O anti-Taylor: sobre a invenção de um método para co-governar instituições de saúde produzindo liberdade e compromisso. Cad. Saude Publica, v.14, n.4, p.863-70, 1998.

CAMPOS, G.W.S.; CARPINTERO, M.C.; BUENO, J.M.S. Protocolo de acolhimento da Secretaria Municipal de Saúde de Campinas. 2001. Disponível em: <http:// www.campinas.sp.gov.br/saude/programas/protocolos/protocolo_acolhimento.htm >. Acesso em: 23 ago. 2005.

CARNEIRO, J.R.; SILVEIRA, C. Organização das práticas de atenção primária em saúde no contexto dos processos de exclusão/inclusão social. Cad. Saude Publica, v.19, n.6, p.182735, 2003.

CARVALHO, S.R.; CUNHA, C.T. A gestão da atenção na saúde: Elementos para se pensar a mudança da organização na saúde. In: CAMPOS, G.W.S. et al. (Orgs.). Tratado de Saúde Coletiva. São Paulo: Hucitec, 2006. p.837-68.

CORDIOLI, A.V.; ZIMMERMANN, H.H.; KESSLER, F. Rotina de avaliação do estado mental. 2004. Disponível em: <http://www.ufrgs.br/psiq/Avalia\% C3\% A7\% C3\% A30\% 20\%20do\%20Estado\%20Mental.pdf>. Acesso em: 22 maio 2008.

COSTEIRA, A. Acolhimento. Sobral: escola de formação em saúde da família Visconde de Sabóia, [s/d]. Disponível em: <http://www.esf.org.br/publicacoes/artigos/artigos1.php>. Acesso em: 23 jun. 2006.

DEJOURS, C.A. O trabalho entre sofrimento e prazer. In: social. Rio de Janeiro: Fundação Getúlio Vargas, 1999. p.27-36.

A banalização da injustiça

DEMENECK, K.A. Características da atenção primária à saúde. Arq. Catarin. Med., v.37, n.1, p.84-90, 2008.

FRANCO, T.B.; BUENO, W.S.; MERHY, E.E. O acolhimento e os processos de trabalho em saúde: o caso de Betim, Minas Gerais, Brasil. Cad. Saude Publica, v.15, n.2, p.345-53, 1999.

GODBOUT, J.T. Digressão sobre as redes e os aparelhos. In: MARTINS, P.H.; FONTES, B. (Orgs.). Redes sociais e saúde: novas possibilidades teóricas. Recife: Editora Universitária da UFPE, 2004. p.77-90.

GOLDIM, J.S. Compaixão, simpatia e empatia. 2006. Disponível em: <http:// www.ufrgs.br/bioetica/compaix.htm>. Acesso em: 24 maio 2008.

GOLEMAN, D. Emotional Intelligence. In: SADOCK, B.J.; SADOCK, V.A. (Eds.). Kaplan \& Sadock's comprehensive textbook of psychiatry. 7.ed. Philadelphia: Lippincott, Williams \& Wilkins, 1999

HELMAN, C.G. Cultura, saúde e doença. 4.ed. Porto Alegre: Artmed, 2003.

. The application of anthropological methods in general practice research. Family Practice, v.13, supl.1, p.S13-6, 1996.

LAPLANTINE, F. Aprender antropologia. São Paulo: Brasiliense, 2000.

LIMA, M.A.D.S. et al. Acesso e acolhimento em unidades de saúde na visão dos usuários. Acta Paul. Enferm., v.20, n.1, p.12-7, 2007.

MALTA, D.C. et al. Acolhimento - uma reconfiguração do processo de trabalho em saúde usuário-centrada. In: REIS, A.T. et al. (Orgs.). Sistema Único de Saúde em Belo Horizonte: reescrevendo o público. São Paulo: Xamã, 1998. p.121-42.

MANLEY, M.R.S. Psychiatric interview, history, and mental status examination. In: SADOCK, B.J.; SADOCK, V.A. (Eds.). Kaplan \& Sadock's comprehensive textbook of psychiatry. 7.ed. Philadelphia: Lippincott, Williams \& Wilkins, 1999. p.652-65. 
MATURANA, H. A ontologia da realidade. Belo Horizonte: Editora UFMG, 1997.

MAYEMA, M.A. (Org.). A construção do acolhimento: a proposta de mudança do processo de trabalho em saúde do município de Bombinhas. Bombinhas: Secretaria Municipal de Saúde, 2007.

MERHY, E.E. A perda da dimensão cuidadora na produção de saúde. In: REIS, A.T. et al. (Orgs.). Sistema Único de Saúde em Belo Horizonte: reescrevendo o público. São Paulo: Xamã, 1998. p.143-60.

MINAYO, M.C.S. (Org.). Pesquisa social: teoria, método e criatividade. 26.ed. Petrópolis: Vozes, 2007.

MORINAGA, C.V. et al. Frases que resumem os atributos na relação médico-paciente. Rev. Bras. Educ. Med., v.26, n.1, p.21-7, 2002.

OLIVEIRA, A. et al. A comunicação no contexto do acolhimento em uma unidade de saúde da família em São Carlos, São Paulo. Interface - Comunic., Saude, Educ., v.12, n.27, p.74962, 2008.

OLIVEIRA, F.A. Antropologia nos serviços de saúde: integralidade, cultura e comunicação. Interface - Comunic., Saude, Educ., v.6, n.10, p.63-74, 2002.

OLIVEIRA, L.M.L.; TUNINI, A.S.M.; SILVA, F.C. Acolhimento: concepções, implicações no processo de trabalho e na atenção em saúde. Rev. APS, v.11, n.4, p.362-73, 2008.

PANIZZI, M.; FRANCO, T.B. A implantação do Acolher Chapecó reorganizando o processo de trabalho. In: FRANCO, T.B. et al. (Orgs.). Acolher Chapecó: uma experiência de mudança do modelo assistencial com base no processo de trabalho. São Paulo: Hucitec, 2004. p.79-110.

PINAFO, E.; LIMA, J.V.C.; BADUY, R.S. Acolhimento: concepção dos auxiliares de enfermagem e percepção de usuários em uma unidade de saúde da família. Rev. Espaç. Saude, v.9, n.2, p.17-25, 2008. Disponível em: <http://www.ccs.uel.br/espacoparasaude/ v9n2/Artigo\%2053-2007\%20_Editado_.pdf>. Acesso em: 28 abr. 2009.

PIRES, D.E.P. Divisão social do trabalho. In: ESCOLA POLITÉCNICA DE SAÚDE JOAQUIM VENÂNCIO (Org.). Dicionário da educação profissional em saúde. Rio de Janeiro: EPSJV, 2006a. v.1. p.87-92.

Divisão técnica do trabalho em saúde. In: ESCOLA POLITÉCNICA DE SAÚDE JOAQUIM VENÂNCIO (Org.). Dicionário da educação profissional em saúde. Rio de Janeiro: EPSJV, 2006b. v.1. p.92-7.

RAMOS, D.D.; LIMA, M.A.D.S. Acesso e acolhimento aos usuários em uma unidade de saúde de Porto Alegre, Rio Grande do Sul, Brasil. Cad. Saude Publica, v.19, n.1, p.27-34, 2003.

ROMANO, V.F. As travestis no Programa Saúde da Família da Lapa. Saude Soc., v.17, n.2, p.211-9, 2008.

SADOCK, B.J. Signs and symptoms in Psychiatry. In: SADOCK, B.J.; SADOCK, V.A. (Eds.). Kaplan \& Sadock's comprehensive textbook of psychiatry. 7.ed. Philadelphia: Lippincott, Williams \& Wilkins, 1999. p.677-89.

SCHIMITH, M.D.; LIMA, M.A.D.S. Acolhimento e vínculo em uma equipe do Programa Saúde da Família. Cad. Saude Publica, v.20, n.6, p.1487-94, 2004.

SCHOLZE, A.S.; SILVA, Y.F. Riscos potenciais à saúde em itinerários de cura e cuidado. Cogitare Enf., v.10, n.2, p.9-16, 2005.

SERRANO, A.I.; BENITO, G.A.V.; GIORDANI-SERRANO, T.R. Interdisciplinaridade no planejamento, na gestão e no trabalho de saúde pública. In: SAUPE, R.; WENDHAUSEN, A.L.P. (Orgs.). Interdisciplinaridade e saúde. Itajaí: Editora Universidade do Vale do Itajaí, 2007. p.173-89. 
SILVEIRA, P.F. O Acolher Chapecó. In: FRANCO, T.B. et al. (Orgs.). Acolher Chapecó: uma experiência de mudança do modelo assistencial com base no processo de trabalho. São Paulo: Hucitec, 2004. p.70-8.

SOLLA, J.J.S.P. Acolhimento no sistema municipal de saúde. Rev. Bras. Saude Mater. Infant., v.5, n.4, p.493-503, 2005.

SOUZA, E.C.F. et al. Acesso e acolhimento na atenção básica: uma análise da percepção dos usuários e profissionais de saúde. Cad. Saude Publica, v.24, supl.1, p.S100-10, 2008.

TAKEMOTO, M.L.S.; SILVA, E.M. Acolhimento e transformações no processo de trabalho de enfermagem em unidades básicas de saúde de Campinas, São Paulo, Brasil. Cad. Saude Publica, v.23, n.2, p.331-40, 2007.

TEIXEIRA, R. Humanização e atenção primária à saúde. Cienc. Saude Colet., v.10, n.3, p.585-97, 2005.

As redes de trabalho afetivo e a contribuição da saúde para a emergência de uma outra concepção de público. 2004. Disponível em: <http://www.corposem.org/rizoma/ redeafetiva.htm>. Acesso em: 23 abr. 2008.

TESSER, C.D.; LUZ, M.T. Uma introdução às contribuições da epistemologia contemporânea para a medicina. Cienc. Saude Colet., v.7, n.2, p.363-72, 2002.

TRESSE, V.P. Acolhimento e vínculo na assistência prestada ao portador de diabetes em uma unidade básica de saúde no município do Rio de Janeiro. 2008. Dissertação (Mestrado) - Escola Nacional de Saúde Pública, Fundação Oswaldo Cruz, Rio de Janeiro. 2008.

TRIGO, T.R.; TENG, C.T.; HALLAK, J.E.C. Síndrome de burnout ou estafa profissional e os transtornos psiquiátricos. Rev. Psiquiatr. Clín., v.34, n.5, p.223-33, 2007.

ZARIFIAN, P. O tempo do trabalho: o tempo-devir frente ao tempo espacializado. Tempo Soc., v.14, n.2, p.1-18, 2002.

SCHOLZE, A.S.; DUARTE JUNIOR, C.F.; FLORES E SILVA, Y. Trabajo en salud y la implantación de la acogida en la atención primaria a la salud: ¿afecto, empatía o alteridad?. Interface - Comunic., Saude, Educ., v.13, n.31, p.303-14, out./dez. 2009.

Desarrollamos una reflexión teórica sabre el trabajo en la Atención Primaria a la Salud (APS) en la directriz de la acogida, buscando posibilidades de superar la alienación en su proceso productivo a partir de relatos de experiencia de la implantación de la acogida en servicios de APS. Identificamos las siguientes perspectivas teóricas en las relaciones interpersonales en los servicios, con indicadores de avances en la humanización del trabajo en salud y de una aproximación con la subjetividad: afecto, empatía y alteridad. Aunque todas sean adecuadas y basta complementarias entre sí, hacemos nuestra opción par la alteridad como perspectiva teórica capaz de instrumentalizar al trabajador de la salud para desarrollar la acogida sin dejar de garantizar su propia humanización. De este modo se abren posibilidades de afrontar las situaciones cotidianas de los servicios de salud, ofreciendo a los profesionales condiciones de construir su trabajo sin limitarlo a la perspectiva biomédica y de preservar su propia salud.

Palabras clave: Acogimiento. Servicios de salud. Atención primaria de salud. Investigación interdisciplinaria. 